\title{
0 Direito à Infância na Escola: por uma Educação contra a Barbárie ${ }^{1}$
}

\author{
Jucirema Quinteiro \\ Centro de Ciências da Educação \\ Universidade Federal de Santa Catarina/Brasil \\ jquinteiro@ig.com.br
}

$\mathrm{O}$ direito à infância na escola emerge como objeto deste trabalho a partir de um conjunto de observações, estudos e reflexões a respeito das questões e dos dilemas que envolvem o processo de democratização do ensino no Brasil que, em última instância, coloca sobre a criança a responsabilidade pelo fracasso da escola pública. Tal fenômeno evidencia-se na "pedagogia da repetência", consequência do autoritarismo que permeia a sociedade brasileira e que na escola se manifesta de modo a perseguir a "criança pobre".

A banalização dos princípios de autonomia, participação e descentralização produzida ao longo das duas últimas décadas no interior do processo de democratização do e no país, somada à crença de que a repetência possa ser um instrumento eficaz de recuperação da aprendizagem, fortemente arraigada entre os professores das escolas públicas brasileiras, tem, na prática, aprofundado as desigualdades sociais e provocado uma perda anual de mais de $25 \%$ do total de crianças, estudantes matriculados no ensino fundamental. Por outro lado, alerta Sérgio Costa Ribeiro, "a probabilidade de um aluno repetente ser aprovado é metade da de um aluno novo na série". Resumidamente, pode-se evidenciar o caráter perverso desta crença, sobretudo, diante das características socioeconomica da criança multirrepetente, que, com frequência, mora em casas precárias e longe da escola. Como afirmou Maria Helena Souza Patto no Colóquio sobre as Classes de Aceleração, realizado em 8/9/1997, na PUC/SP, 'há, sobretudo, uma profunda inimizade dos professores por alunos e seus familiares, tidos como responsáveis pelas dificuldades de ensino e aprendizagem. Responsabilização realizada também por uma psicologia que naturaliza o social e que tem ido na mesma direção do preconceito social contra os pobres, vistos como 'coisas' incapazes" (Colóquio sobre Programas de Classes de Aceleração, 1998, p. 35).

\footnotetext{
1 . Este texto foi apresentado no $2^{\circ}$ Congresso Nacional _ “A Escola entre o Estado e o Mercado: o Público e o Privado na Regulação da Educação", realizado em Lisboa, nos dias 15, 16 e 17 de Maio de 2003

2 . Tal fenomeno foi investigado pela própria autora na sua tese de doutoramento intitulada Infância e Escola: urna relação marcada por preconceitos, defendida no ano de 2000 junto ao Programa de Pós-graduação da Unicamp/SP
} 
Mesmo levando em conta as razões frequentemente alegadas pela maioria dos professores, de que os estudantes "reprovam" por carências sociais e "falta de bases", e, ainda, de que a reprovação constitui uma "sacudidela" para que o aluno possa se tornar mais responsável no ano seguinte, o fenomeno da repetência, neste país, é tão grave que tais justificativas parecem ser insuficientes. Sabemos que os altos índices de repetência escolar atingem todos os países periféricos, com incidência maior na América Latina, sendo o Brasil o país onde estes se apresentam como os mais elevados, ao lado da Guatemala, da Bolivia e da Colômbia. Além disso, os estudos recentes indicam que o abandono não está, primordialmente, vinculado às precárias condições de vida das famílias dos estudantes, mas, na maioria das vezes, trata-se de uma consequência das sucessivas reprovações, manifestando-se, sobretudo, pelo abandono do ano letivo, nos últimos meses, quando o aluno (a) percebe (sente) que não será aprovado ${ }^{3}$.

Observa-se, pois, que a crença na repetência está mais associada a uma visão ingenua de mundo por parte do professor, à indisciplina, à bagunça, ao não cumprimento das normas impostas pela escola, à falta de higiene dos alunos, enfim, vincula-se mais às questões de carácter moral e menos àquelas pertinentes à aquisição de conhecimentos. Isto reforça a tese de que o fenomeno do autoritarismo manifesta-se na escola também através de uma certa tendência para cultivar a reprovação. Isto é, constitui-se em mais uma "invenção" da escola e pode ser melhor observado mediante os chamados Conselhos de Classes, onde se decide, entre outros aspectos escolares, a respeito da aprovação ou reprovação das crianças, alunos do ensino fundamental.

Nesta perspectiva, a definição da escola brasileira formulada por Sérgio Adorno não deixa dúvidas. Segundo este autor,

a escola expulsa seus tutelados através de sutis, porém poderosos mecanismos. Suas práticas não raro, se mostram incompatíveis com o universo cultural de crianças e adolescentes insubmissos. Constituida em espaço sóbrio, destituído de emoções e atracções lúdicas, espaço desinteressante e desmotivador, ela contrasta com o universo cultural no qual os desafios, os confrontos, as lutas, o mundo do tête-à-tête, a vida eminentemente feita de pessoas e não de abstrações constituem seus traços mais significativos (1993) (grifo meu).

Por outro lado, embora as crianças tenham conquistado para si um conjunto de direitos fundamentais, próprios e inalienáveis aos quais se associaram praticamente todos os países do mundo sintetizados nos princípios de proteção, provisão e participação, o Relatório sobre a

\footnotetext{
3 . RIBEIRO, Sérgio C. A educação e a inserção do Brasil na modernidade. Cadernos de Pesquisa, São Paulo, FCC, n 84,.1993
} 
Situação Mundial da Infância-2002, elaborado pela UNICEF, mostra que a condição social da criança não é animadora sob nenhum aspecto.

Segundo um outro Relatório da UNICEF sobre a Situação da Infância, do ano 2001, apesar de o Brasil indicar uma queda no índice de mortalidade infantil, a meta estabelecida de redução em um terço neste período não foi alcançada. Cabe lembrar que ainda vivemos com problemas de sub-registro, que, além de violar o Direito da Criança a um nome e a uma identidade, difículta o acesso desta a serviços de saúde e educação. Certamente, os desafios que o Brasil precisa superar não são novos, nem pequenos. Englobam desde a mortalidade de mulheres e crianças até situações especiais de vulnerabilidade, como o trabalho infantil, os maus-tratos, o abuso, a violência e a privação dos direitos mais elementares da pessoa humana, até à erradicação da fome e da pobreza.

Interessa aqui observar que, até ao final da década de 80, nenhuma constituição havia ainda se referido a direitos específicos da criança. Historicamente, tais direitos aparecem relacionados e justificados pelo Direito à Família e à Assistência. No Brasil, a partir da Constituição de 1988, registram-se pela primeira vez os direitos especificos da criança. Logo depois, o governo brasileiro sancionou a Lei 8.069 de 13 de Julho de 1990, que dispõe sobre o Estatuto da Criança e do Adolescente-ECA, e, através do Decreto Legislativo de 28 de 14 de Setembro de 1990, aprovou o texto da Convenção sobre os Direitos da Criança-CDC, adotada pela Assembleia Geral das Nações Unidas, em Novembro de 1989. Entretanto, os direitos de proteção, provisão e participação não foram e não estão sendo suficientemente respeitados para que as crianças e adolescentes obtivessem, nas últimas quatro décadas, uma melhoria substancial nas suas condições de vida. Pesquisas mostram que, no Brasil, o aprofundamento das desigualdades sociais fazem das crianças o grupo etário onde há explícitos indicadores de pobreza e de violência ${ }^{4}$. Neste contexto a idéia de infância apresenta-se como sinonimo de criança, expressão utilizada para denominar o "filho do rico", e "menor", quando se refere ao "filho do pobre".

\footnotetext{
4 . Entre a bibliografia existente no Brasil sobre a questão da repetência e abanono escolar, dois artigos podem ser destacados por tratar-se de pesquisa de carácter socioetnográfico, mas, principalmente, pela profundidade e a abrangência das suas análises. São eles: Paiva, Vanilda et ai. (1998). 'Revolução Educacional e Contradições da Massificação do Ensino'. Paiva, Vanilda (1998). onsiderações sobre Três Pesquisas Realizadas em Escolas Brasileiras”.
} 
Parece que a ideia que se estabeleceu de que "criança pobre" é sinonimo de "classes perigosas" acabou perpassando a cultura escolar, instalando-se sutilmente nas entrelinhas do currículo e nas práticas sociais e pedagógicas que se realizam no interior da escola.

Diante deste contexto, pergunta-se: que elementos devem constituir uma educação contra a barbárie? Qual tem sido o papel da escola brasileira na construção social da infância? Como rever as funções sociais da escola imprimindo-lhe um sentido que responda de algum modo às expectativas das crianças, estudantes do ensino básico? Será que ainda é possível sonhar com $a$ ideia da infância na escola?, ou tal articulação está sendo esgarçada/rompida pela erosão do sentimento de infância provocado pelas rígidas regras da sociedade de mercado? Será que a tese da escola como lugar da infância constitui uma promessa ou dívida da Modernidade? Afinal, se esta se tomou uma frase cara ao contexto cultural da Modernidade, afirma Heloísa Femandes, é também, porque "foi tematizada, justificada, realimentada pelos inúmeros campos do saber da própria modernidade - pedagogia, sociologia, psicologia, pediatria, psicanálise, etc. — os quais contraíram uma dívida de fundação com ela" (cf. 1996: 60-61).

\section{Alguns pressupostos teórico-metodológicos da escola como lugar da infância}

A proposição de uma educação contra a barbárie defendida por Theodor Adorno readquire significado e importância ainda maior diante da realidade deste início de milenio, pois constituise ponto de partida e de chegada de qualquer proposta de mudança social, uma vez que a barbárie é núcleo da própria civilização (cf. 1995: 119). Tal proposição torna-se fundamental na defesa do direito à infância na escola $e$ na redefinição das finalidades e das práticas pedagógicas, sociais e políticas desta, uma vez que as condições que geram a barbárie parecem assentar no campo das relações que se estabelecem no interior do próprio processo de formação do sujeito. Como escreve Adorno, "dentre os conhecimentos proporcionados por Freud, efectivamente relacionados inclusive à cultura e à sociologia, um dos mais perspicazes parece-me ser aquele de que a civilização, por seu turno, origina e fortalece progressivamente o que é anticivilizatório (ibidem.: 119) (grifo meu). Assim, a educação e a escola, especificamente, adquirem sentido e 
significado ético, ao cumprir com o seu papel social de universalizar os instrumentos necessários que permitam emancipar e minimizar este "estado de natureza" humana.

Entretanto, apavora pensar que a utopia política da modernidade, que defende a formação de “cidadãos livres, dotados de autonomia de vontade, capazes de orientar seu comportamento por meios racionais e ciosos de que, vivendo a experiência da liberdade individual, podem conhecer e participar do mundo das liberdades públicas" (Cambi, 2000), ainda não foi, no Brasil, transformada num projecto de educação generalizado. Tudo isto, somado às características do processo de democratização das oportunidades educacionais neste país, leva a crer que a busca por uma Escola Pública Democrática e de Qualidade parece ser, ainda, um projecto para o futuro, o que coloca em xeque, de um lado, as relações entre a política e a pesquisa educacional e, de outro, o modo como a "criança pobre" é tratada na escola, e, ainda, entre ambas ${ }^{5}$.

Na realidade,

[...] como muitos países, o Brasil participou da grande revolução educacional que caracterizou os 50 anos pós-guerra e que levou oportunidades educacionais a conjuntos populacionais cada vez mais numerosos por um número cada vez maior de anos[...]. Em cinco décadas o sistema de ensino fundamental multiplicou por 10 seu número de matrículas iniciais, saltando de 3,3 milhões em 1945 para cerca de 33 milhões em 1995, num período em que a população não chegou a multiplicar-se por quatro. Foi neste mesmo movimento que também transformamos a escola tradicional, reproduzida nos moldes das reformas dos anos vinte e em especial da de 1928 no Distrito Federal até os anos sessenta, na escola de massa que chega hoje aos mais escondidos rincões de pequenas e médias cidades e das grandes metrópoles (cf. Carta do Rio de Janeiro pela Renovação do Ensino Fundamental, 1998: 7-8) (grifo meu).

Importa observar que tais conceitos, escola tradicional e escola popular de massas, devem ser entendidos como "constructos que resultam da observação do quotidiano escolar, por um lado exacerbam suas características para torná-lo abstracto e típico-ideal e por outro se situa aquém da riqueza apresentada pelo dia-a-dia da escola" (ibid.: 53-54). Frente a esta expansão e à do direito à infância na escola, as perguntas básicas a serem respondidas pelo Brasil são: quais são as

\footnotetext{
5 . Paiva, no seu artigo sobre Pesquisa Educacional e Decisão Política apresentado no II Seminário Internacional sobre Novas Políticas Educacionais: críticas e perspectivas, realizado em 1997 pelo Programa de Estudos Pós-Graduados em Educação: História e Filosofia da Educação da PUC/SP, escreve: 'Perguntar- se sobre a relação entre pesquisa educacional e decisão política significa introduzir, de saída, pelo menos duas questões: a da relevância da pesquisa e seus produtos e a da competência, sensibilidade, conhecimento da área de atuação e projeto político subjacente à ação dos tomadores de decisão. Em ambos os casos, é preciso longo período de maturação política. É preciso tempo e maturidade para conseguir que os temas de pesquisa escolhidos sejam pertinentes, relevantes, capazes de trazer novos conhecimentos, considerando as condições periféricas do País" (Paiva, 1998a: 125) (grifo meu).
} 
implicações desta revolução democrática silenciosa? Em que se distingue esta escola de massa da escola tradicional da qual muitos são saudosos [...] Que funções preenchia a escola tradicional, multiplicada quando a maioria da população se encontrava no campo e que nas cidades atendia as camadas médias, e que funções preenche hoje esta escola que invadiu as áreas pobres e foi invadida por uma população que the era estranha e distante: o aluno verdadeiramente pobre?' (ibid.: 8) (grifo meu).

As proposições de uma educação contra a barbárie e o direito a infancia na escola, sem dúvida nenhuma, colocam em xeque o carácter homogeneizador desta instituição, levando-a a uma revisão radical dos mecanismos que sustentam a estrutura, o funcionamento e a organização escolar actual, possibilitando a construção de uma pedagogia capaz de respeitar a criança como um sujeito de direitos. A crença no papel da escola como fator de democratização vincula-se ao conceito de educação como prática social, na qual está subjacente certa visão de mundo, e ainda ao entendimento de que sendo as escolas construídas para as crianças - nos níveis político e organizacional e nos planos histórico e das políticas educativas — elas também são - no plano da ação concreta - construidas (sobretudo) pelas crianças (Montadon, 1997 apud Sarmento, 2001).

Ciente de que o fenómeno do fracasso escolar não é uma consequência necessária da democratização e de que o nível de riqueza social e a sua distribuição são determinantes para a escola e para o aproveitamento que podemos ter desta, acredito ainda na função histórica da escola, na sua potencialidade emancipadora. Considerando o direito à infância na escola, e especialmente as expectativas manifestadas pelas crianças, estudantes do ensino fundamental, torna-se necessário mudar tal organização social tanto na sua essência quanto na sua aparência, abordando tal fenómeno sob outros parâmetros.

Tal proposição exige uma ética que valorize os aspectos sociais e políticos da relação entre infância e escola, pois "educar $e$ ensinar, é colocar alguém em presença de certos elementos da cultura a fim de que ele deles se nutra, que ele os incorpore à sua substância, que ele construa a sua identidade intelectual e pessoal em função deles". Ora, tal projeto repousa necessariamente 
sobre uma concepção seletiva e normativa da cultura, no sentido de um "mundo humanamente construído, mundo das instituições e dos signos no qual, desde a origem, se banha todo individuo" (Forquin, 1993: 167-168).

Neste sentido, a escola é também:

[...] um mundo social, que tem suas características e vida próprias, seus ritmos e seus ritos, sua linguagem, seu imaginário, seus modos próprios de regulação e de transgressão, seu regime próprio de produção e gestão de símbolos. E esta cultura da escola (no sentido em que se pode também falar da cultura da oficina ou da cultura da prisão) não deve ser confundida tão-pouco com o que se entende por cultura escolar, que se pode definir como um conjunto de conteúdos cognitivos e simbólicos que, selecionados, organizados, normalizados, rotinizados, sob o efeito de imperativos de didatização, constituem habitualmente o objeto de uma transmissão deliberada no contexto das escolas (Forquin, 1993: 167). (grifo do autor)

Garantir o acesso à cultura em geral, e à cultura escolar em particular, impõe uma outra reflexão a respeito de a escola ser ainda "um lugar específico [...], pois, somente aqui se obtêm respostas a questões que não seriam jamais colocadas em outros lugares. Aqui a herança da experiência humana é comunicada sob a forma mais 'universal' possível, isto é, também a menos 'concreta', a menos pertinente em relação às interrogações pontuais, aleatórias ou rotineiras suscitadas pelas situações triviais da vida" (Forquin, 1993:169) (grifo meu).

Tendo a escola um papel particular e ao mesmo tempo fundamental a desempenhar na história da sociedade contemporânea, consequentemente as relações sociais aí estabelecidas devem ser também redefinidas. Nesta perspectiva, um dos parâmetros volta-se para a superação do tipo de relação de poder que se estabelece entre a professora e o(a) estudantes, que vem se caracterizando como uma cultura responsável pela expulsão de milhares de crianças, pois "fundada em mitos, preconceitos, hábitos rotineiros, segregadores - enfim, crenças travestidas de conhecimentos científicos. É comum no discurso das professoras o argumento de que as crianças não aprendem porque são pobres, sujas, desnutridas, imaturas, negras, nordestinas, ou ainda que elas não aprendem porque os seus os pais são analfabetos, alcoólatras, e as mães trabalham fora (Moysés \& Coilares, 1993, p12).

Este conjunto de valores e crenças revela o carácter marcadamente ideológico das representações que a professora tem das crianças, estudantes do ensino básico, manifestando, entre outros 
aspectos, uma concepção idílica e idealista de criança, que, por sua vez, influencia e caracteriza a prática pedagógica.

Superar tais culturas produzidas socialmente exige, entre outros aspectos, uma mudança de mentalidade direcionada à tomada de uma consciência de classe, que permita à professora compreender-se como ser social, buscando ultrapassar os limites do senso-comum que configuram tal cultura e, concomitaritemente, alterar tanto as suas relações de trabalho quanto as condições objetivas da prática educativa. Este processo a levará a considerar a criança como um ser histórico, concreto, determinado pelo contexto das relações sociais de produção da existência humana, tal como ela mesma o é.

Considerando que a escola se constitui num modelo social que tem características próprias, a pesquisa sobre a cultura da escola necessita de uma abordagem na qual o olhar do pesquisador se dirija para os processos mais particulares e contingentes da escola, privilegiando a análise das dimensões culturais: o quotidiano, as interações sociais, as relações de poder, as experiências escolares tanto das crianças como dos adultos, os saberes construídos, reproduzidos e transformados no seu interior, que fazem da escola uma instituição marcadamente diferente de outra. Metodologicamente, os estudos sobre a cultura da escola (Fourquin, 1993; Nóvoa, 1995; Barroso, 1996; Sarmento, 2000 e 2001; Benito, 2000; Benjamin, 1984, 1986, 1975, 1994 e 1995; Boole, 1984 e 1987; Demartini, 2000 e 2002; Candau, 1998; Canário, 1996; Rockwell \& Ezpleleta, 1985 e 1986; Kramer, 2000) sugerem o uso de abordagens etnográficas mais abrangentes, de longa e profunda imersão no campo, necessárias à realização de uma descrição e análise densa sobre escola.

Embora a análise das culturas infantis e suas articulações com as instituições para a infância, especialmente a escola, seja indicada como um tema relevante nos estudos sociológicos da infância, pouco se conhece sobre as culturas infantis, porque pouco se ouve e pouco se pergunta às crianças e, ainda assim, quando isto acontece, a "fala" apresenta-se solta no texto, intacta, à margem das interpretações e análises dos pesquisadores. Estes parecem ficar prisioneiros dos seus próprios referenciais de análise. Entre as Ciências da Educação, no âmbito da Sociologia, há 
ainda resistência em aceitar o testemunho infantil como fonte de pesquisa confiável e respeitável. Além disso, apesar de a etnografia e a história oral serem indicadas pelos pesquisadores como recursos metodológicos eficientes no registro do "ponto de vista" das crianças - a entrevista, tal qual a concebemos, tem-se mostrado como um instrumento pouco adequado quando utilizada junto a este "pequeno sujeito" ou "pequeno objecto" emergente. Muitos pesquisadores, ao entrevistarem a criança na pesquisa educacional, não problematizam os dados, tão pouco descrevem nos seus textos os elementos constitutivos do processo de recolha da voz da criança (cf. Quinteiro, 2002).

Ainda que existam muitas lacunas e hiatos na produção do conhecimento sobre a infância e educação no Brasil, há que se reconhecer que o esforço empreendido por alguns pesquisadores, nas últimas décadas, tem contribuído, como já afirmou Kramer, para "forjar outro olhar à infância, e não apenas sobre ela" (Kramer, 1996: 26) (grifo meu).

Os saberes constituídos sobre a infância que estão ao nosso alcance até ao momento permitemnos conhecer mais sobre as precárias condições sociais das crianças brasileiras, sobre sua história e sua condição profundamente adversa de "adulto em miniatura", e pouco sobre o que sentem e pensam, sobre os seus próprios saberes, as suas práticas e possibilidades de criar e recriar a realidade social na qual se encontram inseridas. Afinal, o que sabemos sobre as culturas infantis? O que conhecemos sobre os modos de vida das crianças indígenas, negras, brancas? O que sabemos sobre as crianças que frequentam a escola pública? Como aprendem? Como criam? O que aprendem? O que sentem? O que pensam? Ressalta-se, ainda, que as relações de poder entre o adulto e a criança, tema elementar para a compreensão das culturas infantis, ainda estão por serem estudadas, tanto local quanto internacionalmente ${ }^{6}$.

\section{O direito à infância na escola como um projeto de intervenção sociológica}

\footnotetext{
${ }^{6}$. Narodowski, na sua tese de doutoramento defendida na Unicamp e publicada pela Ed. Aiqiie, Buenos Aires, sob o título 'Infância e Poder: la conformación de la pedagogia moderna', identifica um núcleo de consenso entre os historiadores acerca da definição de infância. Para o autor, "a infância é fenómeno histórico e não meramente natural, e as características da mesma no ocidente moderno podem ser esquematicamente delineadas a partir da heteronomia, da dependência e da obediência ao adulto em troca de protecção"(1994: 173) .
} 
No sentido mais amplo, tal projeto busca discutir a relação entre a infância e a escola no sentido de tentar compreender as contradições do processo de democratização do ensino, marcado pela reforma protestante e pela revolução industrial, pelas pressões exercidas pelo movimento dos trabalhadores e também pelas doutrinas liberais. Mais especificamente, este projeto busca entender como os fios da infância foram sendo tecidos aos fios da escola, configurando-se nesta formulação que, sem dúvida, se constitui numa das teses mais caras à Modernidade: o lugar da infância é na escola!

$\mathrm{Na}$ realidade, tal projecto encontra-se em desenvolvimento desde 2000, e parte da ideia da escola como lugar privilegiado da infância ${ }^{7}$, e dos princípios de indissociabilidade entre ensino, pesquisa e extensão, junto a um grupo constituído por 200 crianças, estudantes dos anos iniciais do ensino fundamental, bem como de um outro grupo composto por 25 professores que atuam do pré-escolar ao oitavo ano, numa escola pública, localizada em Florianópolis/SC. Todas as ações aí desenvolvidas apresentam-se articuladas e estruturadas a partir dos seguintes projetos: o Projeto de Ensino visa contribuir na Formação universitária do professor e realiza-se por meio do estágio docente nos anos iniciais do Ensino Fundamental do Curso de Pedagogia, tendo como estratégia didáctico-metodológica veicular os direitos sociais constantes no Estatuto da Criança e do Adolescente-ECA junto das próprias crianças, e ainda discutir as forças que o negam e as formas de lutar, visando desenvolver a sua capacidade de expressão, reflexão e crítica mediante a difícil, porém necessária, articulação entre o ensinar e o brincar no interior da escola. O Projeto de Pesquisa encontra-se vinculado a este e busca conhecer "O que pensam, sentem, dizem, escrevem e desenham as crianças" sobre Ser criança no mundo e na escola. Finalmente, o Projeto de Extensão caracteriza-se por um Programa de Formação Continuada junto de 25 professores que atuam do pré-escolar até à oitava séries, e tem como objetivo a elaboração do Projeto político-Pedagógico da escola pautado na promoção e valorização dos direitos das crianças, mediante a participação direta dos sujeitos na construção da tão desejada autonomia da escola.

\footnotetext{
7 . Este não deve ser um projeto de apenas um pesquisador, mas de muitos; assim sendo integra o Grupo de Estudos e Pesquisa sobre Educação, Infância e Escola-GEPIEE, e tem por objetivo investigar as bases epistemológicas da relação entre infância e escola pública. Para tanto, define alguns parâmetros teórico-metodológicos que possibilitam articular os diferentes aspectos e dimensões do problema investigado: estudos teóricos sobre a relação entre Educação, Modernidade, lnfância e Escola; Tempo e Espaço da Infância na escola; Participação Infantil na gestão da escola; análises das Representações das crianças; e um Levantamento bibliográfico da produção existente sobre a sociologia (da infância e da escola) no Brasil, as suas características e tendências.
} 
Deste modo, os objetivos deste trabalho são, por um lado, conhecer a criança que está no aluno a partir da análise das suas representações, buscando vê-la e ouvi-la a respeito de como pensa e concebe o mundo e a escola. Por outro lado, busca contribuir no processo de formação do professor, tanto a universtária como a continuada, objetivando ampliar o seu raio de leitura a respeito dos limites e das possibilidades da escola como lugar da infância. Posto isto, algumas questões se colocam: qual o lugar da infância na escola e na formação do professor para a educação básica?; qual o sentido da escola para a criança/estudante?; quais as dimensões política e pedagógica da participação da criança na escola?

Finalmente, a ideia da infância na escola vincula-se à ideia de uma sociedade justa e democrática orientada por uma educação contra a barbárie, e isto exige uma ética e uma política que valorizem o professor através de salários justos e dignos, e principalmente que ofereçam as condições para uma formação crítica e para se trabalhar com a criança como sujeito das relações sociais concretas, sem preconceitos, sem juízos prévios, nem manifestações verbais que possam subtrair a sua dignidade pessoal. Reorganizar o tempo e o espaço escolares no sentido não apenas de garantir o acesso, mas principalmente transformar a escola num lugar agradável, aonde a criança goste de ir e permanecer não só por "obrigação", mas também porque se encontra mobilizada para participar do seu próprio processo formativo. Este parece ser o desafio do presente!

\section{REFERÊNCIAS BIBLIOGRÁFICAS}

ADORNO, Sérgio (1993). A experiência precoce da punição. la: MA.RTINS, José de Souza (org). $\boldsymbol{O}$ Massacre dos Inocentes: a criança sem infância no Brasil. São Paulo: Hucitec, 1993b. pp.181-208.

ADORNO, Theodor W. (1995). Educação após Auschwitz. la: Educação e Emancipação. São Paulo: Paz e Teira, 1995a. pp. 119-138.

BENITO, Augustin Escolano (2000). Culturas escolares. mimeog. Trabalho apresentado no Congresso Luso-Brasileiro de História da Educação, 3, Coimbra, Portugal, 2000.

BENJAMIN, Walter (1984). Reflexões: a criança, o brinquedo e a educação. 4' ed. São Paulo: Summus. 
BENJAMIN, Walter. (1986). Documentos de cultura. Documentos de barbárie. São Paulo: Cutrix-Ed. da USP.

BENJAMIN, Walter. (1975).A modernidade e os modernos. Rio de Janeiro: Tempo Brasileiro.

BENJAMIN, Walter. (1994). Magia e técnica, arte e política: ensaios sobre literatura e história da cultura. 7? ed. São Paulo: Brasiliense. Vol. 1: Obras Escolhidas.

BENJAMIN, Walter. (1995). Rua de mão única. $5^{\text {a }}$ ed., São Paulo: Brasiliense, Vol. II: Obras Escolhidas.

BOLLE, Wiili. (1984). Walter Benjamin e a cultura da criança, IN: Reflexões: a criança, o brinquedo, a educação. São Paulo, Surnmus. pp. 13-16.

BOLLE, Willi. (1987). A modernidade segundo Walter Benjamin. Revista da Universidade de São Paulo. São Paulo, n? 5, pp. 45-56.

(1997). A ideia de formação na modernidade, IN: GHIRALDELLI, Paulo (org.). Infância, escola e modernidade. São Paulo: Cortez:. pp. 9-32.

CAMBI, Franco. (1999). A História da Pedagogia. Trad. Alvaro Lorencini. SP: Ed. Unesp.

CANÁRIO, Rui. (1996). Os Estudos sobre a Escola: problemas e perspectivas, IN BARROSO, João

(org.). O estudo da escola. Porto: Porto Editora.

CANDAU, Vera Maria. (1998). Mudanças culturais e redefinição do escolar. Revista Contemporaneidade e Educação, São Paulo, ano ifi, n? 3, pp. 14-26.

CARTA DO RIO DE JANEIRO PELA RENOVAÇÃO DO ENSINO FUNDAMENTAL.(1998). Revista Contemporaneidade e Educação, ano ifi, n ' 3, pp. 7-13.

COLÓQUIO sobre Programa de Classes de Aceleração (1998). São Paulo: Cortez, Pontificia Universidade Católica de São Paulo: Acção Educativa, (Série Debates; 7).

DEMARTINI, Zeila (2000). Culturas escolares: algumas questões para a história da educação. mimeog. Trabalho apresentado no III Congresso Luso-Brasileiro de História da Educação, 3, Coimbra, Portugal, 2000 .

DEMARTINI, Zeila de Brito Fabri (2002). Infância, pesquisa e relatos orais. IN: FARIA, Ana Lúcia G. de; DEMARTINI, Zeila de B. F.; PRADO, Patrícia Dias (orgs.). Por uma cultura da infância:

metodologias de pesquisa com crianças. Campinas: Autores Associados, pp.1-17. (Colecção Educação Contemporânea).

EZPELETA, Justa \& ROCKWELL, Elsie. (1986). Pesquisa participante. São Paulo: Cortez.

EZPELETA, Justa (1985). A construção social da escola. Revista Brasileira de Estudos Pedagógicos. Vol. 66, n? 152, pp. 106-19, Jan/Abr.

FERNANDES, Heloisa (1996). Infância e modernidade: doença do olhar. Revista Plural; Sociologia, São Paulo, USP, n³, pp. 60-81, 1’ sem.

FORQUIN, Jean-Claude (1993). Escola e cultura: as bases sociais e epistemológícas do conhecimento escolar. Porto Alegre: Artes Médicas. 
KRAMER, Sôma (2000). Politicas para a infância, formação cultural e educação contra a barbárie: paradoxos e desafios da contemporaneidade. la: Congresso Internacional: os mundos sociais e culturais da infância. Braga/Portugal, actas 1, Jan.

MOYSÉS, M. A; COLLARES, Cecilia A. L. (1993). Sobre alguns preconceitos no quotidiano escolar. Ideias. São Paulo: FDE, n? 19, pp. 9-25.

NÓVOA, A. (1995). Para uma análise das instituições escolares. IN: As organizações escolares em análise. (org. António Nóvoa). Lisboa: Dom Quixote.

PAIVA, Vanilda (1998). Considerações sobre três pesquisas realizadas em escolas brasileiras. Revista Ensaio - Avaliação e Políticas Pú.blicas em Educação. Pio de Janeiro:

Fundação Cesgranrio, vol. 6, n? 18, pp. 7-23.

PAIVA, Vanilda (1998b). Pesquisa educacional e decisão politica. In: WARDE, Mirian Jorge (org.). Novas políticas educacionais: criticas e perspectivas. São Paulo: Programa de Estudos Pós-Graduados em Educação História e Filosofia da Educação da Pontifícia Universidade Católica de São Paulo, pp. 125138.

PAIVA, Vanilda (1998c) et ai. Revolução educacional e contradições da massificação do ensino. Revista Contemporaneidade e Educação, Ano III, n 3, pp. 44-99.

QUINTEIRO, Jucirema (2002). Infância e Educação no Brasil: um campo de estudos em construção. IN: FARIA, Ana Lúcia G. de; DEMABTINI, Zeila de B. F.; PRADO, Patrícia Dias (orgs.). Por uma cultura da infância: metodologias de pesquisa com crianças. Campinas: Autores Associados, pp. 19-47. (Colecção Educação Contemporânea)

SARMENTO, Manuel J. Lógicas de acção nas escolas. Braga: Instituto de Inovação Educacional, (Ciências da Educação; 38).2000.

SOARES, Natália Fernandes. Direitos da criança: utopia ou realidade? IN: PINTO, Manuel \& SARMENTO, Manuel J. (coord). As crianças - contextos e identidades. Braga: Portugal: Centro de Estudos da Criança: pp. 7-28.

UNICEF. Situação Mundial da Infância (2001). (www.unicef.oro.). UNICEF. Situação da Infância Brasileira (2002).(www.unicef.orc). 